\title{
The "Flipped Classroom": A Tool for Higher Education in Times of Confinement
}

Dr. Laura Georgina Carmona-García, Dr. J. Emilio Méndez-González ${ }^{*}$, M.A. Lorena Araceli López-Guzmán, M.A.R.H. Liliana Álvarez-Loya

Fulltime Teachers in Business Management, Administrative Audit and Entrepreneurship Development in Accounting and Management FacultyAutonomous University of Chihuahua UACh, México

| Received: 11.12 .2020 | Accepted: 21.12.2020 | Published: 30.12.2020

*Corresponding author: J. Emilio Méndez-González

\section{Abstract}

Education must meet the needs required by today's students; the new generations known as the Net Generation; they demand an updated educational system. There are multiple teaching systems at the higher level, some focused on the use of competencies, as well as on Bloom's Taxonomy; having as a common goal, professionals prepared for globalization when exercising their profession. It is critical to be at the forefront of changes in tools that facilitate the cognitive process. The mechanism of the methodology developed in the "Flipped Classroom" is reviewed, with the "Bloom's Taxonomy", since the latter is the preamble for the design of various educational models. The Flipped class is an integration strategy, strengthens the educational process, and helps in the administration of the student and the teacher's time, meeting learning requirements, interacting with the Tics that the student executes, being the learning process dynamic, and adaptable to the learning capacity, achieving their attention, generating knowledge through their experiences, and expanding it with that of their peers.

Keywords: "Flipped Classroom", Higher Education, Bloom's Taxonomy, ICTs, Confinement.

Copyright $\odot \mathbf{2 0 2 0}$ The Author(s): This is an open-access article distributed under the terms of the Creative Commons Attribution 4.0 International License (CC BY-NC 4.0) which permits unrestricted use, distribution, and reproduction in any medium for non-commercial use provided the original author and source are credited.

\section{INTRODUCTION}

Education has to satisfy the needs required by today's students; the new generations known as the Net Generation; they demand an updated educational system.

There are multiple teaching systems at the higher level, some focused on the use of competencies, as well as on Bloom's Taxonomy; having as a common goal, professionals prepared for globalization when exercising their profession.

The Net Generation Oblinger [4] is defined by the technological advances that are available to everyone, an evolution never thought of has been achieved through cyberspace, which has allowed to streamline social development, in several aspects, cities have been called smart cities, The industry has evolved in such a way that a machine supplies thousands of personnel, and manages to produce in a matter of seconds, what was achieved in months or years, and these advances require that everything be at this established level, the agility of life Today, it leads the student to have to function in a working way, without having to abandon their studies, is what has generated these changes, in the daily.

It is essential to be at the forefront of this evolution, to advance tools that facilitate and streamline the cognitive process.

The mechanism of the methodology developed in the "Flipped Classroom" is reviewed, with the "Bloom's Taxonomy", since the latter is the preamble for the design of various educational models.

The "Flipped Class" is an integration strategy, strengthens the educational process, and helps in the administration of the student and the teacher's time, meeting learning requirements, interacting with the Tics that the student executes, being the learning process dynamic, and adaptable to the learning capacity, achieving their attention, generating knowledge through their experiences, and expanding it with that of their peers. 
By establishing the relationship that occurs in these two learning techniques, the "Flipped Classroom" technique is strengthened, giving the student a strengthened tool, which contains the most important aspects, which have been studied in the Bloom model, which has been recognized for clearly showing the learning process.

Flip teaching or "Flipped Classroom" is a form of teaching-learning system in which students learn new content online by watching video lectures, usually at home, and what used to be homework (assigned problems) is now done in class with teacher offering more personalized guidance and interaction with students, instead of lecturing. This is also known as backwards classroom, reverse instruction, flipping the classroom and reverse teaching.

The "Flipped Classroom" was initially seen as a modality of education, today it became a necessity, since it is perceived as one of the best schemes in learning in times of pandemic, in turn allows a complete educational process, giving it a role with defined activities and schemes for both the student and the teacher, following an order that allows a response of knowledge generated and acquired by the student.

The issue is transcendental, since at present some universities were in very monotonous situations, pigeonholed in the educational model that presents the teacher as the main actor, in some models such as that of competencies, although the teacher is only a guide, falls into the old role of being the tenor of knowledge, without giving opportunity to the student's own experience, in this development of education, the need to dispense with the classroom and a direct interaction of its authors, student-teacher, was never envisioned. it was certainly taken without seeing how complicated it would be to face a situation of a global disease whose determining factor is physical interaction, through which contagion occurs. Nowadays, it has caused educational institutions to be learning centers in the process of updating to a virtual modality or, where appropriate, already updated at this time, as well as the consequences of this change, they become great challenges to continue instructing students in this new mode.

The "Flipped Classroom" has changed the role of the instructor or teacher in the training of the student, its main objective being to provide information to the students in a different way that encourages them to generate their own experience, in the same way it suffers a change in the role of the student, who now he has a greater degree of responsibility for his learning because he must involve more his activities in virtual platforms.

\section{Development}

The "Flipped Classroom" - "Upside down classroom", "backwards classroom", "reverse instruction", "flipping the classroom" and "reverse teaching" is a didactic strategy, characterized by a teaching method that has changed the traditional learning model, provides greater emphasis on practice, but still, it does not have a uniform definition. The concept of Quiroga A [6] defines it as: "A pedagogical approach in which direct instruction moves the student from a collective learning space to an individual learning space, and the space of the resulting collective learning is transformed into a dynamic and interactive learning environment, where the teacher guides the students as he applies the concepts and participates creatively in the subject" Vidal Ledo [8].

One of the first antecedents is the work of Walvoord \& Johnson Anderson [9]. The authors proposed a model where the students, before class, must develop the contents; Then, in the class, the understanding of the content is promoted (synthesize, analyze, solve problems) through active learning, with the aim of ensuring that the students carry out the necessary preparation for the work in the classroom, they had to carry out a series of activities (essays, quizzes, forums.) before class. Velásquez [7]

This educational model or tool complies with the necessary interaction to fulfill the objective of the learning process, being the presentation of the information by the teacher, while the assimilation and feedback is by the student.

The process is carried out when the teacher designs the necessary material, which is sent to the student through videos, readings and activities that the student will review before the class; The student will have the material reviewed and the previous activities carried out, which will allow that, in the face-to-face class, it will be a review and feedback on what the student assimilated.

Professional education is a determining stage in the life of the student, since from this, formality is established to develop in the workplace, companies demand qualified employees to develop the activities established in the analysis of the position, and in the same way the fee, must have a series of skills not only labor as we mentioned, in the same way attitudinal skills, which allow making decisions, have assertiveness and entrepreneurship, teamwork, leadership, to mention a few.

The virtual classroom technique allows the student to receive the information, prior to the face-toface class, to see the need to comply with the subject, carry out activities, as well as develop the application of 
the information given by the teacher, the context of the environment in which it takes place.

The reasoning that Descartes studied in his philosophy, who establishes this inherent and individual activity of thought, which is personal and unique, becomes a fundamental part of this technique, since one of the advantages in this method is the development of knowledge, which we could call self-learning that occurs in the student, since it is he who executes the subject and develops it in a personal way and can access the information presented by the teacher, again and again according to his level of learning, and the most advantageous, which subsequently receives feedback in the face-to-face class, exposing its developed theme and concluding with the experience and perspective of its classmates, being directed by the teacher, whose function will be to reinforce and correct the ideas presented, giving a complete learning process.

"The greatest enemy of knowledge is not ignorance, it is the illusion of knowledge", said Stephen Hawking

Oblinger [4] in Understanding the Net Gen Nontraditional Learners, notes that at the same time that colleges and universities are graduating their first Net Generation learners, most campuses are experiencing an influx of nontraditional students; Three-quarters of all undergraduates are "nontraditional," according to the National Center for Educational Statistics. Nontraditional students are defined as having one or more of the following characteristics:

- Delayed enrollment-did not enter postsecondary education in the same year they graduated from high school

- Attend part-time, for all or part of the academic year Work full time-35 hours or more-while enrolled

- Financially independent as defined by financial aid

- Have dependents, other than a spouse, which may include children or others

- Single parent, having one or more dependent children

- Lack of a high school diploma

\section{Bloom Taxonomy Model}

It is important to review the contributions of the "Instructional Design of education", in which, over time, training materials have been developed and applied to the evaluation of the science of learning, marking the trends in education that have been impregnated by This design, one of the most outstanding was undoubtedly the contribution to Bloom's taxonomy.

Bloom's Taxonomy, an important link in education, since its model implies the instructional process that must be generated in the student so that knowledge is obtained. Benjamin Bloom presented a classification of "The Objectives of the Educational Process", where it is determined what elements the student must carry out for the knowledge process to take place, it is not an isolated activity, nor is it achieved with a single interaction, or having access to knowledge establishes that it is necessary to carry out a simulation, application and evaluation of what has been learned to confirm that there is indeed learning on the subject. Actions were identified in which the domain of knowledge, the affective part and the psychomotor or sensory part must be involved for learning to exist.

Bloom establishes a hierarchy in learning, a series of situations that have an established order, which is referred to as "Bloom's Taxonomy", which determines that knowledge must be presented following a line from the simplest to the most complex behavior, is a reference of various models developed and applied mostly in higher education, it is not unique or perfect, but it adapts easily to the development of competences, which also signify in the field of professional level instruction.

In the task of classifying the objectives of education, Bloom's taxonomy is determined, who defines the cognitive dimension as the ability to think about things. Cognitive goals revolve around knowledge and understanding of any given topic, Bloom [1]. There are six levels in the taxonomy, in ascending order they are as follows:

1. Knowledge. Shows recall of previously learned materials through evocable facts, terms, basic concepts, and responses.

2. Comprehension. Demonstrative understanding of facts and ideas by organizing, comparing, translating, interpreting, describing, and formulating main ideas

3. Application. Use of new knowledge. Solve problems in new situations by applying acquired knowledge, facts, techniques and rules in a different way.

4. Analysis. Examination and discrimination of information identifying motives or causes. Make inferences and find evidence to support generalizations

5. Synthesis. Compilation of information in different ways combining elements in a new pattern or proposing alternative solutions

6. Evaluation. Presenting and defending opinions by judging information, the validity of ideas, or the quality of a work against a set of criteria.

Table-1 shows the complement between the "Flipped Classroom" dynamic and Bloom's Taxonomy, where it is summarized that it complies with all the considerations of the instructional design of education, 
facing a proposal that is complemented and improved with the inclusion of the Bloom's taxonomy.

Table-1: Bloom-"Flipped Classroom" Gear

\begin{tabular}{|l|l|}
\hline $\begin{array}{l}\text { BLOOM'S } \\
\text { TAXONOMY }\end{array}$ & "FLIPPED CLASSROOM" \\
\hline KNOWLEDGE & It is carried out through the material presented by the teacher \\
\hline APPLICATION & It will be carried out, when executing the required activities prior to the face-to-face class \\
\hline UNDERSTANDING & The student will understand the material in a self-taught way and will be given feedback later \\
\hline ANALYSIS & $\begin{array}{l}\text { The analysis is favored, since the student has access to the material to review it, as many times } \\
\text { as he considers necessary and assimilate it to his level of knowledge. }\end{array}$ \\
\hline SYNTHESIS & $\begin{array}{l}\text { In preparing for the face-to-face class, the student creates their own learning perspective to } \\
\text { present in class }\end{array}$ \\
\hline EVALUATION & $\begin{array}{l}\text { It is evaluated both; by the teacher and by the student, since the feedback will expose what has } \\
\text { been learned }\end{array}$ \\
\hline
\end{tabular}

It is possible to determine that these two elements support the relationship that exists in the development of learning competencies, learning by competencies, has been the basis for most higher education programs, a series of margins have been implemented conceptual about the knowledge that generates skills in students, but not only in knowing, but in being, and doing, so that we develop knowledge by learning and unlearning from situations, adapting them to the context of time and place; if it is need to be a leader in a position, be trained and skilled, for another activity you need to be inclusive and selective or work as a team, it will never be the same for the various work activities.

Competencies are aptitudes that are used to convey the meaning of what the person is capable of, being competent to execute, the degree of preparation, sufficiency or responsibility for certain tasks as necessary Prieto [5].

Kane [2] defines it as the degree of use of knowledge, skills and good judgment associated with the profession, in all situations that can be faced in the exercise of professional practice, which we have highlighted is generated based on the experience of each person and their scope of development.

The competences do not signify the person as the domain of all aspects, since in this it infers the character or manner of performance of each one; but it does include that ability to successfully develop a certain action, which is acquired through learning Kellerman [3].

Higher education is the basis, since it is necessary in the growth of a country, business development, the integration of the elements that are part of an integral education is established, as they allow the integral reinforcement of Education at the higher level, supporting students who work and study, allowing efficient study in time and form, and promoting the development of the necessary skills of knowing, being and doing, in the margin of Bloom's taxonomy, ensuring the process of knowledge.

At present, the universities of the world were not prepared to face the current health situation that we live in; In the use of technologies, they were only part of the operating and administrative systems for the development of activities but they were not so required for the training of students, so that today it is already necessary to use technology and systems such as means of alternatives in learning, while taking the "Flipped Classroom" as an opportunity as a tool to face these challenges that arise from the beginning of the pandemic, to current and future times.

\section{MATERIAL AND METHODS}

The research carried out is of a documentary, bibliographic type, since information issued regarding the study models was collected, information was reviewed on the aspects that occupy and are involved in the definition of learning systems and teaching methods, it is transversal and historical, since it is through time that these are modified and perfected and have been determining the validity of the information.

The information collected is not considered extensive since they are new topics, but there is a clear relationship in the information, so that the established objectives can be concluded, giving scope for new topics to be studied and more lines of research are established.

The information reviewed is not extensive, since the topic of the "Flipped Classroom" is new, and many of its elements are still missing to be certified, there are few sources of information that exist in our country, so the application of the method in other countries was reviewed countries, understanding that there are differences in advances and access to technology, this being the basis for the application of the "Flipped Classroom". 


\section{CONCLUSION}

The "Flipped Classroom" is undoubtedly a valid tool in the teaching of higher education, since it implies a level of skill and knowledge to carry out the interaction that is necessary for the knowledge to be executed, it reinforces the competence that demands skill, and the student is placed in a virtual environment necessary for many of the work activities that are carried out today.

It is necessary to establish the communication of companies and University institutions, as this allows the requirements of employment sources to be met, so as not to saturate the student with knowledge who would not execute them at work.

When developing an educational plan, it is important to cover the key points for the subject or career to be offered, the competencies that are necessary to comprehensively cover the program, and it is reinforced with the bloom taxonomy, reinforcing learning and generating a guide. based on this model, so that knowledge occurs; and the "Flipped Classroom", promotes the facility for the student to execute the information provided over and over again, generate their knowledge and direct it towards the personal objectives that each student has as a priority, and pay them with the feedback of the face-to-face class that will be used more effectively, on doubts, corrections and generating a joint knowledge of various experiences, which are influenced by those that the student considers most transcendental.

Not everything is favorable for the execution of this model, it also implies a maturity and interest on the part of the student to achieve knowledge, because if the activity of the Flipped class were not developed as such, he would find a disoriented student, wasting the class of feedback and lost in comments or interaction activities; It is undoubtedly a model that is considered adequate for a professional level, because it implies its application to its environment, which would be difficult in a student of a high school level or lower.

Teacher training is another important point, because the information that will reach the student depends on this, and the activities that will be carried out to capture the teaching, so that only the feedback is seen in the classroom; The teacher has the obligation to develop accessible, digestible material for the student and that has elements to urge the student to go beyond reviewing the lesson and developing it mediocrely.

Another disadvantage that may be present is the accessibility to the network, or to a computer equipment, by students, mainly in rural areas with little access to the network; However, today in the rest of the country, most young people are distinguished by being always connected to the networks, which encourages interaction with the model, making it novel and attractive for students, which allows the management of their time, without forgetting the initial foundation of this tool, which was designed to solve the student's absences in the classroom.

The teacher is a transcendental point in the application of the "Flipped Classroom", since it implies his interest in coupling the material of the subject, in such a way that he organizes and presents the information to the student at the level that is necessary, it has not been evaluated so that subjects is convenient and in which there could be some complication, speaking of subjects that carry numerical calculations, it is not discarded in its entirety, because by presenting tutorial videos, perhaps they reinforce the teaching of this subject by being accessible the explanation, as many times as necessary to the student their review.

Another point of importance is to emphasize that this tool is only a means, not an end, it could not replace the teacher and it would not be convenient to omit the face-to-face class, since it generates feedback and closure of the topic.

This "Flipped Classroom" model is not only in responding to continence, but also in the educational evolution, which by necessity became an indispensable tool for the development of academic activities, which is why the use of digital technologies should be promoted. and schemes, for alternative learning, must be present in universities as a permanent tool.

\section{RECOMMENDATIONS}

It is necessary to expand the research, cover various topics that allow to achieve the improvement of the "Flipped Classroom" tool, the benefits that will be achieved by carrying it correctly are great, there are still no quantitative references that evaluate its effectiveness more accurately, it is recommended abound in the subject, giving values that reflect the strengths and weaknesses perceived in the proposed system, from the point of view of the students, who are the ones who develop learning, and of the teachers who will face the demand for training and innovation, not only in sending the information and the subsequent face-to-face evaluation, but also in the preparation of the material, in the accessibility of the information; It will be of great contribution to evaluate experimentally the complications that are perceived in the application of this methodology in different learning areas, and to determine if it is optional for all types of subjects.

Promote the use of systems and technologies in institutions for application in teachers and students, this evolution is forced in cultural changes, it must be promoted to modify teaching models and make that transition towards the use of technologies in education 


\section{REFERENCES}

1. Bloom, B. S. (1956). Taxonomy of educational objectives: The classification of educational goals: Handbook I, cognitive domain. New York; Toronto: Longmans, Green. New York; Toronto: Longmans, Green.

2. Kane, M. T. (1992). An argument-based approach to validity. Psychological Bulletin, 112 (3), 527535.

3. Kellerman, N. P. F. (2001). Psychopathology in children of Holocaust survivors: A review of the research literature. Israel Journal of Psychiatry and Related Sciences, 38(1), 36-46.

4. Oblinger, D. G. (2005). Educating the Net Generation. Retrieved November 2018, from EDUCAUSE: http://www.educause.edu/ir/library/pdf/pub7101.p df

5. Prieto, J. M., (2002): Prologue. Levy-Leboyer Claude: Management of competencies, Gestión 2000, SA, Barcelona.
6. Quiroga, A. (2015, April 11). Gran Colombiano Polytechnic. Retrieved November 2020, from Education Observatory Definition of "Flipped Classroom": http://crear.poligran.edu.co/?p=1177

7. Velásquez, R. R. (2017, June 26). Is the "Flipped Classroom" really effective? Retrieved November 2020, from Iberoamerica Divulga: /www.oei.es/historico/divulgacioncientifica/?Esefectiva-realmente-el-aula-invertida-o-flippedclassroom

8. Vidal Ledo, M. R. (2020, November 25). scielo. Retrieved from "Flipped Classroom", new didactic strategy. Higher Medical Education: http://scielo.sld.cu/scielo.php?script=sci_arttext\&p $\mathrm{id}=$ S0864-21412016000300020\&lng=es\&tlng=es.

9. Walvoord, B., \& Johnson Anderson, V. (1998). Effective grading: A tool for learning and assessment. San Francisco: Jossey-Bass. 